\title{
PENGEMBANGAN MEDIA PEMBELAJARAN BOX QUESTION PADA MATERI SISTEM KOLOID DI MA SITI MARIAM BANJARMASIN
}

\section{Development Of Learning Box Question Media On Colloid System Material In Ma Siti Mariam Banjarmasin}

\author{
Putri Pertiwi , Novrian Dony, Mohan Taufiq Mashuri \\ Program Studi Pendidikan Kimia Fakultas Keguruan dan Ilmu Pendidikan \\ Universitas Islam Kalimantan (Uniska) Muhammad Arsyad Al Banjari, Banjarmasin \\ email: putrippertiwi@gmail.com
}

\begin{abstract}
Abstrak.Penelitian ini bertujuan untuk menghasilkan media box question yang layak sebagai sarana bagi siswa untuk mengulangi materi koloid yang telah diajarkan agar lebih aktif dan fokus mengikuti pembelajaran pada materi sistem koloid di MA Siti Mariam Banjarmasin. Metode penelitian ini menggunakan metode R\&D dengan model ADDIE (analysis, design, development, implemention, and evaluation). Teknik analisis data yang digunakan oleh penilii yakni berupa deskriftif kualitatif. Hasil analisis angket validitas media box question oleh ahli di peroleh rata-rata $51,6 \%$ berada pada rentang $51<\mathrm{X} \leq 63$ sehingga termasuk kriteria baik (B). Hasil analisis angket uji kelayakan media box question setelah implemention pada siswa diperoleh rata-rata 52,2 \% berada pada rentang $X>50,4$ sehingga termasuk kriteria sangat baik (A), dengan pengamatan pada hasil angket semua siswa berperan aktif saat media ini digunakan. Setelah di implementasikan dan berdasarkan hasil angket dapat disimpulakan bahwa media box question yang dihasilkan sudah layak digunakan untuk bahan pembelajaran.
\end{abstract}

Kata kunci : Kimia, Sistem Koloid, Penelitian Pengembangan, Media Box Question

\begin{abstract}
This study aims to produce a feasible box question media as a tool for students to repeat colloidal material that has been taught to make them more active and focus in learning colloidal system material at MA Siti Mariam Banjarmasin. This research method uses the R\&D method with the ADDIE model (analysis, design, development, implementation, and evaluation). The data analysis technique used by the reviewers is in the form of qualitative descriptive. The results of the questionnaire analysis for box question media validity by experts obtained an average of $51.6 \%$ in the range of $51<X \leq 63$ so that it included the good criteria (B). The results of the questionnaire analysis for the box question media feasibility
\end{abstract}


after the implementation obtained an average of $52.2 \%$ in the range $X>50.4$ so that it is included in excellent criteria (A), with observations on the results of the questionnaire all students played an active role when the media was used. After it has been implemented, based on the results of the questionnaire, it can be concluded that the box question media is appropriate to be used for learning materials.

Keywords : Chemistry, Colloidal System, Research Development, Box Question Media

\section{PENDAHULUAN}

Salah satu materi pokok dalam pembelajaran kimia yang di pelajari di kelas XI SMA/MA adalah materi sistem koloid. Pengetahuan faktual, pengetahuan konseptual, dan pengetahuan prosedural banyak terdapat di dalam materi sistem koloid. Sesuai dengan karakteristik materi tersebut, diperlukan suatu usaha seperti banyak membaca, berdiskusi, dan mengerjakan latihan agar tercapai indikator pencapaian kompetensi materi sistem koloid yang sesuai dengan kurikulum 2013 (Gomulya \& Iswendi, 2018). Salah satu standar kompetensi tersebut terdiri dari dua kompetensi dasar (KD) yaitu mengenal berbagai jenis sistem koloid disekitar serta memahami pengelompokan dan penerapan sistem koloid dalam kehidupan sehari-hari (Padmanaba dkk, 2018).

Di MA Siti Mariam Banjarmasin, siswa kurang aktif terhadap pembelajaran kimia dalam kegiatan belajar mengajar. Di sekolah, guru menggunakan metode ceramah dimana pembelajaran sebagian besar berpusat pada guru. Adapun media yang sering dipakai pada saat pembelajaran adalah power point. Guru telah berusaha mengajar dengan sebaik-baiknya tetapi masih saja ditemukan beberapa siswa yang tidak bisa menjawab pertanyaan saat pengulangan materi akibat siswa tidak fokus saat pembelajaran berlangsung. Menurut guru, siswa tidak tertarik dengan pengulangan materi dan latihan soal karena tingkat kejenuhan dan tidak fokus saat pembelajaran. Hal ini juga berhubungan dengan topik yang dipelajari, yaitu sistem koloid, dimana guru lebih banyak menjelaskan mengenai teori dan prinsip yang tergolong sulit untuk dipahami siswa sehingga motivasi mereka kurang besar dalam mempelajarinya (Khairunnisa, Akhyar, \& Wardhani, 2019). Saat ini banyak cara yang dapat di terapkan guru agar tercapainya tujuan pembelajaran dengan digunakan berbagai strategi dan metode pembelajaran, salah satunya yang terbaik adalah menggunakan media pembelajaran (Gomulya \& Iswendi, 2018). Pengembangan media pembelajaran menandakan kedinamisan pendidikan yang memicu pendidik untuk lebih aktif, kreatif, dan inovatif (Rosalina, Wardhani, \& Akhyar, 2018). Media pembelajaran memiliki peranan yang penting dalam pencapaian keberhasilan belajar peserta didik. Media merupakan segala sesuatu yang dapat digunakan untuk menyalurkan pesan, merangsang pikiran, perasaan, perhatian dan kemauan peserta didik sehingga peserta didik dapat terdorong dan terlibat dalam proses pembelajaran. (Wisnari dkk, 2017). Menurut peneliti, sejauh ini untuk menanggulangi permasalahan siswa banyak peneliti yang terdahulu menggunakan media permainan sebagai media pembelajaran seperti Khairunnisa, Akhyar, dan Wardhani (2019) yang sebelumnya telah melakukan penelitian 
tentang pengembangan media wheels question sebagai media pembelajaran untuk meningkatkan motivasi belajar siswa pada materi sistem koloid di SMA Negeri 12 Banjarmasin. Menurut peneliti, media ini memiliki kekurangan yaitu terlalu memakan waktu; saat pemutaran roda jika terlalu kencang maka akan lama rodanya berhenti sehingga waktu belajar tidak mencukupi.

Menurut peneliti untuk mengatasi masalah diatas, maka yang cocok digunakan di MA Siti Mariam Banjarmasin adalah pengembangan suatu media pembelajaran yaitu media box question. Penggunaan media pembelajaran box question diharapkan akan menimbulkan dampak positif terhadap proses pembelajaran untuk membantu siswa dalam memahami materi dengan mudah. Penggunaan media box question dilatar belakangi oleh keadaan siswa yang tidak fokus saat pembelajaran dan suasana kelas yang tidak menarik seperti di MA Siti Mariam Banjarmasin. Media box question atau bisa disebut dengan kotak pertanyaan merupakan media permainan yang dikemas untuk melatih keaktifan siswa dan membuat suasana saat pembelajaran menarik dan tidak tegang dan akan berdampak positif untuk siswa dalam mengikuti pembelajaran di kelas agar siswa lebih memahami materi terutama materi sistem koloid. Permainan ini bisa digunakan pada materi yang dirasa cukup sulit dipahami oleh siswa. Permainan ini juga tidak memerlukan waktu yang banyak. Media box question merupakan media mengajar dengan melemparkan koin ke dalam box dimana setiap box terisi beberapa pilihan warna, kemudian setiap siswa yang melempar koin dan mendarat diwarna yang tersedia akan diberikan pertanyaan yang ada pada kartu soal sesuai warna tersebut.

Pengembangan media box question ini di harapkan mampu menjadi alat bantu pembelajaran untuk siswa agar lebih aktif dalam mengikuti kegiatan pembelajaran dan fokus saat pembelajaran sehingga dapat meningkatkan keaktifan siswa pada materi koloid terutama. Berdasarkan uraian di atas peneliti tertarik membuat judul penelitian yaitu "Pengembangan Media Pembelajaran Box Question pada Materi Sistem Koloid di MA Siti Mariam Banjarmasin”

\section{METODE PENELITIAN}

Model pengembangan yang di gunakan adalah ADDIE. Teknik analisis data yang di gunakan oleh peneliti pada hasil telaah yakni berupa analisis deskriptif dengan memberikan gambaran dan memberikan pemaparan saran terkait media box question. Pada teknik analisis data pada hasil validasi yang di lakukan oleh para ahli dan siswa menggunakan :

Tabel 1. Kritetia Penilaian

\begin{tabular}{|l|l|c|}
\hline No & Kreteria & Rumus \\
\hline 1. & Sangat Baik & $X>\bar{x}_{i}+1,8 \times \mathrm{Sb}_{i}$ \\
\hline 2. & Baik & $\overline{x_{i}}+0,6 \times \mathrm{Sb}_{i}<X \leq \bar{x}_{i}+1,8 \times \mathrm{Sb}_{i}$ \\
\hline 3. & Cukup Baik & $\bar{x}_{i}-0,6 \times \mathrm{Sb}_{i}<X \leq \bar{x} i+0,6 \times \mathrm{Sb}_{i}$ \\
\hline 4. & Kurang Baik & $-\bar{x}_{i}-1,8 \times \mathrm{Sb}_{i}<X \leq \bar{x}_{i}+0,6 \times \mathrm{Sb}_{i}$ \\
\hline 5. & Tidak Baik & $X \leq \bar{x}_{i}+1,8 \times \mathrm{Sb}_{i}$ \\
\hline
\end{tabular}

(cko Putro Widovoko. 2011:238 dalam Dwi.S.R. 2017:50) 
Keterangan :

$$
\begin{aligned}
\mathrm{x}_{\mathrm{i}} & =(\text { rerata ideal }) \\
& =1 / 2(\text { skor maksimum ideal }+ \text { skor minimum ideal }) \\
\mathrm{Sb}_{\mathrm{i}} & =(\text { simapangan baku ideal }) \\
\mathrm{X} & =1 / 6 \text { (skor maksimum ideal }+ \text { skor minimum ideal }) \\
& =(\text { skor empiris })
\end{aligned}
$$

Skor maksimal ideal $=\sum$ butir kriteria $\mathrm{x}$ skor tertinggi

Skor minimal ideal $=\sum$ butir kriteria $\mathrm{x}$ skor terendah

\section{HASIL PENELITIAN DAN PEMBAHASAN}

\section{Hasil Penelitian}

Produk media box question ini diuji kelayakannya hanya menggunakan para ahli setiap aspek penelitiannya. Uji kelayakan ini dilakukan oleh 1 dosen dan 2 guru di MA Siti Mariam Banjarmasin. Adapun hasil uji kelayakan media box question seagai berikut :

Tabel 2. Hasil Uji Kelayakan Produk

\begin{tabular}{|l|l|l|l|l|}
\hline No & Validator & Nilai & Hasil & Kriteria \\
\hline 1 & Validator 1 & 59 & Baik & B \\
\hline 2 & Validator 2 & 54 & Baik & B \\
\hline 3 & Validator 3 & 51 & Baik & B \\
\hline \multicolumn{2}{|l|}{ Rata rata } & 54,6 & Baik & B \\
\hline
\end{tabular}

Dari hasil uji validitas terhadap 1 orang dosen dan 2 orang guru di peroleh data yang rata rata mendapat nilai 54,6 sehingga termasuk nilai (B). Hasil data yang didapat sesudah di revisi oleh peneliti. Peneliti menggunakan media box question setelah mendapat nilai/kriteria layak di gunakan oleh validator. Terbukti dengan respon siswa saat menggunakan media box question.

Berdasarkan hasil yang di peroleh validitas bertujuan untuk medapatkan informasi, kritik, saran tentang media box question yang telah di buat sehingga layak digunakan sebagai media pembelajaran. Validasi kelayakan ahli di lakukan oleh 1 dosen dan 2 guru menyatakan layak digunakan dengan sedikit revisi. Angket validasi memiliki 4 aspek penilaian dengan 5 alternatif jawaban menggunkan skala likert 1 sampai 5 yaitu: sangat baik $=5$, baik $=4$, cukup baik $=3$, kurang baik $=2$, tidak baik $=1$. Setiap penilaian harus dicantumkan komentar tetapi kenyataannya validator hanya mengatakan komentar dengan lisan. Hal ini dapat diartikan bahwa media box question yang dikembangkan sudah memenuhi syarat untuk digunakan sebagai media pembelajaran.

Validator yang pertama adalah dosen pendidikan kimia Universitas Islam Kalimantan Muhammad Arsyad Al-Banjari yaitu ibu Novi Rahmawati, M.Si. Validitas 4 aspek penilaian dengan 15 indikator skor total 59 yang diperoleh pada tabel penentuan kriteria berada pada rentang $51<X \leq 63$ sehingga termasuk nilai (B).

Validator yang kedua adalah guru kimia MA Siti Mariam Banjarmasin yaitu ibu Jamilah, S.Pd. validitas 4 aspek penilaian dengan 15 indikator skor total 54 yang di peroleh pada tabel penentuan kriteria berada pada rentang $51<X \leq 63$ sehingga termasuk kriteria baik (B). 
Validator yang ketiga adalah guru kimia MA Siti Mariam Banjarmasin yaiyu ibu Risnawati, S.Pd. validitas 4 aspek penilaian dengan 15 indikator skor total 51 yang di peroleh pada tabel penentuan kriteria berada pada rentang $51<X \leq 63$ sehingga termasuk kriteria baik (B).

Hasil perhitungan ini didapat dengan rumus sebagai berikut :

Skor maksimal ideal $=\Sigma$ butir kriteria $\mathrm{x}$ skor tertinggi

$$
\begin{aligned}
& =15 \times 5 \\
& =75
\end{aligned}
$$

Skor minimal ideal $=\Sigma$ butir kriteria $\mathrm{x}$ skor terendah

$$
=15 \times 1
$$

$\mathrm{Mi}$

$$
\begin{aligned}
& =15 \\
& =\frac{1}{2}(\text { skor maksimal ideal }+ \text { skor minimal ideal })
\end{aligned}
$$$$
=\frac{1}{2}(75+15)
$$

$$
=45
$$

Sbi

$$
\left.=\frac{1}{2} \times \frac{1}{3} \text { (skor maksimal ideal }- \text { skor minimal ideal }\right)
$$

$$
\begin{aligned}
& =\frac{1}{2} \times \frac{1}{3}(75-15) \\
& =10
\end{aligned}
$$

Produk diuji kepada siswa kelas XI IPA di sekolah. Adapun sekolah yang menjadi tempat uji kelayakan media box question pada materi sistem koloid adalah MA Siti Mariam Banjarmasin. Jumlah siswa pada kelas XI IPA ini adalah 23 orang. Saat pengisian angket ada 1 orang siswa yang tidak hadir karena sakit. Pengisian amgket di lakukan saat penelitian terakhir. Produk ini digunakan setelah materi di jelaskan oleh guru. Adapun hasil uji media box question pada materi sistem koloid adalah sebagai berikut :

Dari hasil respon siswa diperoleh data dengan rata rata 52,2 yang di peroleh pada tabel penentuan kriteria berada pada rentang $X>50,4$ sehingga termasuk kriteria sangat baik (A). Berdasarkan perolehan data tersebut dapat disimpulkan bahwa media pembelajaran yang di kembangkan layak digunakan untuk siswa yang tidak fokus saat pengulangan materi dalam materi koloid. Angket uji kelayakan media box question di validasi oleh 3 validator yaitu 1 dosen dan 2 guru. Angket ini dibuat sendiri oleh peneliti dan sudah dikomsultasikan kepada dosen pembimbing.

Hasil perhitungan ini didapat dengan rumus sebagai berikut :

Skor maksimal ideal $=\Sigma$ butir kriteria $\mathrm{x}$ skor tertinggi

$$
\begin{aligned}
& =12 \times 5 \\
& =60
\end{aligned}
$$

Skor minimal ideal $=\Sigma$ butir kriteria $\mathrm{x}$ skor terendah

$$
=12 \times 1
$$

$\mathrm{Mi}$

$$
\begin{aligned}
= & =12 \\
=\frac{1}{2}(\text { skor } & \text { maksimal ideal }+ \text { skor minimal ideal }) \\
= & \frac{1}{2}(60+12) \\
= & 36
\end{aligned}
$$


Sbi

$$
\begin{gathered}
=\frac{1}{2} \times \frac{1}{3}(\text { skor maksimal ideal }- \text { skor minimal ideal }) \\
=\frac{1}{2} \times \frac{1}{3}(60-12) \\
=8
\end{gathered}
$$

\section{Pembahasan}

\section{Analysis}

Media yang di gunakan adalah media box question. Tahap perencanaan media box question yang ingin di hasilkan adalah media box question yang di desain sebaikbaiknya sehingga siswa tertarik untuk mencoba dan membuat siswa tidak tegang saat pembelajaran. Terbukti saat penggunaan media di dalam kelas siswa sangat santai dan bisa mengikuti permainan dengan baik. Berdasarkan hasil analisis peneliti dengan menggunakannya media boq question di sekolah, saat proses pembelajaran sistem koloid siswa sangat fokus dan membantu siswa saat pengulangan materi yang telah disampaikan oleh guru. Pada saat pengembangan produk peneliti berkonsultasi dengan dosen pembimbing apakah produk ini siap digunakan.

\section{Design}

Dapat dikatakan ini pengembangan produk dimana tujuan dari tahapan ini adalah untuk membuat rancangan media pembelajaran box question. Tujuan yang ingin dicapai adalah dengan menggunakan media box question ini siswa mampu menjawab pertanyaan dari guru saat pengulangan materi sistem koloid. Waktu penelitian ini sudah direncanakan untuk tempat dan waktu penelitian. Perkiraan dana yang di keluarkan dalam pembuatan media box question adalah sebesar Rp 65.000 .

Design media box question terdiri dari box question, kartu soal, koin untuk melempar dan peraturan permainan box question. Bentuk media box question kotak persegi yang di bagi menjadi 6 bagian. Setiap bagian memiliki warna yang berbeda beda yaitu, pink, merah, orange, biru, kuning dan hijau. Ukuran media box question yaitu, panjang $28 \mathrm{~cm}$ lebar $45 \mathrm{~cm}$. Setiap bagian memiliki ukuran panjang $14 \mathrm{~cm}$ lebar 10,5 $\mathrm{cm}$. Media box question dapat dilihat pada gambar 1 .

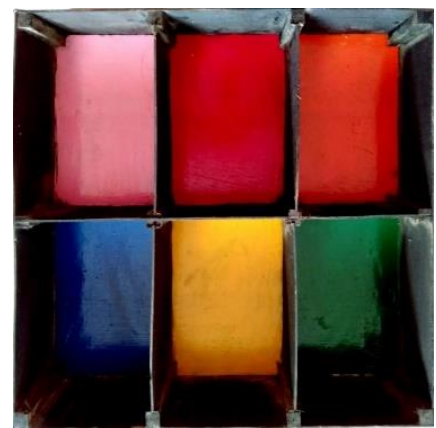

Gambar 1. Media Box Question 
Media box question digunakan dalam bentuk permainan. Untuk mencapai suasana yang menarik dan dapat diterima oleh siswa dirancanglah peraturan permainan. Peraturan permainan media pembelajaran box question di buat sebagai berikut :

1) Guru membagi siswa menjadi beberapa kelompok di mana masing masing kelompok ada yang beranggotakan 4 dan ada yang beranggotakan 5 .

2) Setiap kelompok mempersiapkan satu orang untuk maju bermain box question secara bergantian.

3) Setiap perwakilan kelompok melempar koin ke dalam box question, dimana koin itu terlempar maka siswa mengambil kartu soal yang sesuai warna.

4) Setelah mengambil kartu soal, maka setiap kelompok harus menyelesaikan soal yang didapat.

5) Jika kelompok tidak bisa menjawab maka pertanyaan akan di lempar ke kelompok lain.

6) Setiap kelompok yang menjawab soal dengan benar akan mendapat 1 point.

Peraturan permainan ini hasil perbaikan permintaan oleh validator dan telah dibuat sesai yang diinginkan oleh validator.Media box question menggunakan sebanyak 54 kartu soal pada seluruh pertemuan tiap pertemuan kartu soal yang digunakan ada kartu setiap warna. Kartu warna merah memiliki 9 kartu, Kartu warna biru memiliki 9 kartu, kartu warna kuning kuning memiliki 9 kartu, kartu warna hijau memiliki 9 kartu, kartu warna orange memiliki 9 kartu, kartu warna biru memiliki 9 kartu. Kartu soal berisi tentang materi sistem koloid yaitu pengertian koloid, jenis jenis koloid, sifat sifat koloid , cara pembuatan koloid dan penerapan nya. Soal yang berada di katu soal sebelumnya di validasi oleh validator.

\section{Development}

Pada tahap ini peneliti menyiapkan apa saja bahan yang diperlukan padasaat membuat media box question, di antaranya seperti jurnal - jurnal yang dapat dijadikan sebagai sumber acuan pembuatan media pembelajaran box question. Setelah sumber sumber sudah siap, maka di buatlah produk dengan mengembangkan perlengkapan membuat box question kemudian menggunakan cat untuk mewarnai setiap bagian kotak yang telah di bagi sama rata kemudian membuat kartu soal yang berbentuk kotak persegi, disetiap kartu ada 6 warna yang berbeda yaitu merah, kuning, hijau, biru, pink dan orange. Setiap katu soal terdapat pertanyaan - pertanyaan yang berkaitan dengan materi yang telah di jelaskan. Hasil desain awal media box question ini dikonsultasikan kepada dosen pembimbing.

Pada tahap ini juga dilakukan validitas produk, yang mana tujuan dari tahap ini adalah untuk memperoleh produk penelitian pengembangan media pembelajaran box question yang di nilai layak oleh ahli. Media ini di validitas oleh 3 orang ahli dengan 4 aspek penilaian. Pengambilan data untuk validitas media ini menggunakan lembar validitas dengan alternative jawaban menggunakan skala likert 1 sampai 5 yaitu, sangat baik $=5$, baik $=4$, cukup baik $=3$, kurang baik $=2$, tidak baik $=1$. Setiap pemilihan jawaban harus di nyatakan komentar tetapi validator hanya menjelaskan dengan lisan apa saja yang harus direvisi. Aspek aspek yang direvisi menurut validator yaitu soal evaluasi siswa setelah menggunakan media box question. 


\section{Implementation}

Penggunaan media box question ini di gunakan setelah materi sistem koloid disampaikan di kelas. Pertemuan pertama guru menyampaikan apersepsi dengan memberikan pertanyaan kepada siswa tentang apakah siswa mengetahui materi sistem koloid sebelum diajarkan guru. Kemudian guru menginformasikan materi yang akan di pelajari. Kemudian menyampaikan tujuan pembelajaran.Tahap selanjutnya yaitu pelaksaan kegiatan inti di mulai dengan menyampaikan materi yang dilanjutkan dengan memberikan contoh. Kemudian setelah menyampaikan materi lalu menggunakan media box question. Saat penggunaan di kelas siswa sangat antusias dalam menggunakan media ini. Siswa menjadi lebih aktif menjawab pertanyaan. Menurut siswa penggunaan media box question membuat mereka menjadi lebih tertantang. Hal ini terbukti dari pernyataan yaitu "Sesuai dengan karakteristik siswa yaitu siswa usia 7-18 tahun cenderung menyukai media permainan dalam kegiatan pembelajaran" (Wahyuni dkk, 2016).

Saat penggunaan media box question terjadi diskusi antar kelompok sehingga siswa menjadi aktif dalam kelompoknya. Saat pengulangan materi setelah menggunakan media box question siswa mampu menjawab pertanyaan secara lisan dengan benar. Penggunaan media ini juga merubah suasana kelas yang awal jenuh belajar koloid setelah itu menjadi tidak tegang. Selama ini di sekolah guru telah berusaha menjelaskan materi dengan menggunakan media power point tetapi saat guru menjelaskan materi siswa menjadi jenuh, tidak fokus dan tegang. Tahap selanjutnya setelah menggunakan media box question guru memberi soal evaluasi kepada siswa. Setelah itu, melakukan pengulangan materi dengan memberi pertanyaan lisan kepada siswa mengenai materi yang di ajarkan tadi. Saat guru bertanya kepada siswa, siswa dapat menjawab pertanyaan guru dengan benar.

Guru menutup pembelajaram bersama siswa dan mengakhiri pembelajaran dengan mengucapkan salam. Pertmuan kedua dan ketiga dilakukan sama seperti pertemuan pertama tetapi saat pertemuan ketiga guru memberikan angket uji kelayakan media kepada siswa setelah pembelajaran selesai.

\section{Evaluation}

Tahap ini melihat respon siswa saat menggunakan media box question layak di gunakan atau tidak. Untuk mengetahui respon siswa di beri angket kelayakan media yang telah dirancak oleh peneliti dan sudah di konsulkan dengan dosen pembimbing. Angket ini memiliki 12 kuisoner dengan alternative jawaban menggunakan skala likert 1 sampai 5 yaitu, sangat baik $=5$, baik $=4$, cukup baik $=3$, kurang baik $=2$, tidak baik $=$ 1. Pada evaluation ini tidak ada revisi dari siswa. Siswa menganggap media ini layak digunakan dan menarik saat digunakan.

\section{SIMPULAN}

Berdasarkan hasil penelitian dan pembahasan maka dapat diambil kesimpulan Pengembangan Media Pembelajaran Box Question pada Materi Sistem Koloid dilakukan dengan mengikuti langkah model ADDIE Media pembelajaran box question telah disusun sesuai dengan angket kelayakan yang sudah diuji sebagai media pembelajaran menurut para ahli dan siswa. Media pembelajaran box question ini secara keseluruhan mampu digunakan sebagai bahan pembelajaran di MA Siti Mariam Banjarmasin. 


\section{DAFTAR PUSTAKA}

Akbar, M, dkk. 2017. Pengembangan Media Pembelajaran Multimedia Interaktif Pada Materi Sistem Koloid. Jurnal. Pendidikan Kimia FKIP Universitas Lambung Mangkurat, Banjarmasin.

Arsyad, A. 2016. Media Pembelajaran. Jakarta : PT Remaja Grafindo Persada.

Gumulya, D.S dan Iswendi.2018. Pengembangan Ludo Word Game (LWG) Kimia sebagai Media Chemo-Edutainment (CET) pada Materi Sistem Koloid Kelas XI SMA/MA. Jurnal. Program Studi Pendidikan Kimia, FMIPA, Universitas Negeri Padang.

Khairunnisa, U., Akhyar, O., \& Wardhani, R. A. (2019). Pengembangan Media Wheels Question pada Materi Sistem Koloid Untuk Meningkatkan Motivasi Belajar Siswa Kelas XI di SMA Negeri 12 Banjarmasin. Dalton: Jurnal Pendidikan Kimia dan Ilmu Kimia, 2(1), 22-27.

Khairunnisa, W. (2017). Pengembangan Media Permainan Roda Putar Berbasis Website Untuk Keterampilan Membaca Bahasa Prancis Siswa Kelas XI SMA AngkasaAdisutjipto.Skripsi. Program Studi Pendidikan Prancis Fakultas Bahasa dan Seni Universitas Negeri Yogyakarta. Yogjakarta.

Mahrus,M. 2015. Meningkatkan Motivasi Belajar Siswa Melalui Media Pembelajaran Audio Visual Pada Mata Pelajaran Akidah Akhlak Di Madrasah Aliyah Negeri (MAN) Bondowoso. Skripsi. Jurusan Pendidikan Agama Islam Universitas Islam Negeri Maulana Malik Ibrahim. MalangMajid, Abdul. 2016. Strategi Pembelajaran. Bandung : PT Remaja Rosdakarya.

Padmanaba, K.G. dkk. 2018. Pengembangan Media Pembelajaran Interaktif Kimia Koloid Berbantuan Komputer Untuk Siswa SMA. Jurnal. Universitas Pendidikan Ganesha, Indonesia.

Rizqianan, F.K, dkk. 2017. Pengembangan Bahan Ajar Kimia Berbasis Investigasi untuk Meningkatkan Kompetensi siswa pada Materi Koloid. Artikel. Pascasarjana, Universitas Negeri Semarang.

Rosalina, S. D., Wardhani, R. A., \& Akhyar, O. (2018). Pengembangan Bahan Pembelajaran Buku Kimia Berbasis Pop Up Pada Materi Minyak Bumi Sebagai Sumber Belajar Mandiri Peserta Didik Kelas X SMAN 12 Banjarmasin. Dalton: Jurnal Pendidikan Kimia dan Ilmu Kimia, 1(1), 34-40.

Sari, P., dkk. 2017. Pengaruh Model Pembelajaran Kooperatif Tipe Teams Games Tournament (TGT) Berbantuan Question Box Terhadap Hasil Belajar Siswa Pada Materi Kelarutan dan Hasil Kali Kelarutan Kelas XI IPA MAN 1 Pontianak. Jurnal. Prodi Pendidikan Kimia FKIP Universitas Muhammadiyah Pontianak.

Sudjana, N. 2013. Dasar-dasar Proses Belajar Mengajar. Bandung: Sinar Baru Algensindo.

Sugiyono. 2015. Metode Penelitian \& pengembangan research and Development. Bandung : Alfabeta, cv. 
Dalton : Jurnal Pendidikan Kimia dan Ilmu Kimia, Volume 2 Nomor 2, November 2019

Wahyuni, E.S. dan Hidayah, R. 2016. Pengembangan Media Permainan Kartu Quarchem Untuk Melatihkan Keterampilan Berpikir Analitis Siswa Pada Materi Ikatan Kimia Kelas X SMA. In Prosiding Seminar Nasional Kimia dan Pembelajaranya, hal. 124-130.

Wisnari, E., dkk. 2017. Pengembangan Media Pembelajaran Berbasis Powtoon pada Pokok Bahasan Koloid di SMA/MA. Jurnal. Program Studi Pendidikan Kimia Fakultas Keguruan dan Ilmu Pendidikan Universitas Riau. 